\title{
PERFORMANCE MIDIÁTICA E CONSTRUÇÃO DO ETHOS DO A(U)TOR: AMÉLIE NOTHOMB
}

\author{
Ana Amélia Gonçalves da Costa ${ }^{1}$
}

\begin{abstract}
RESUMO: Narcisista, egocêntrica, grafômana, excêntrica, polêmica. Esses são alguns dos adjetivos empregados por jornalistas e críticos literários franceses para qualificar Amélie Nothomb, a quem intitulam "escritora-star". A despeito de adjetivações, Nothomb, sucesso incontestável de vendas e de público, encarna publicamente o que a argentina Leonor Arfuch analisa como o sujeito constitutivamente incompleto e, portanto, aberto a identificações múltiplas. Esta identidade ambígua e fluida, para usar o termo forjado pelo sociólogo Zygmunt Bauman, é própria de nossa era. Assim, revestida de paradoxos e andando na corda-bamba dos mal-entendidos, a escritora belga Amélie Nothomb constrói uma personagem midiática, cuja performance inclui uma leitura refletida em sua obra. $\mathrm{Na}$ linha de fronteira entre ficção e realidade - supondo que os dois termos possam se opor -, Amélie Nothomb garante que seu ethos pré-discursivo seja reforçado por seu discurso, possibilidade analisada pelo linguista Dominique Maingueneau.
\end{abstract}

PALAVRAS-CHAVE: identidade, espaço biográfico, ethos, performance.

RESUME : Narcissique, égocentrique, graphomane, excentrique, controversée. Voici quelques-uns des adjectifs déjà employés par des critiques littéraires et des journalistes français pour qualifier Amélie Nothomb, qu'ils appellent « écrivain-star». Malgré ces adjectifs, Nothomb, succès incontestable et de ventes et de public, incarne ce que l'argentine Leonor Arfuch examine comme le sujet « constitutivement » incomplet et, par conséquent, un sujet ouvert à des identifications multiples. Cette identité ambiguë et fluide, afin d'utiliser le terme forgé par le sociologue Zygmunt Bauman, est caractéristique de notre propre époque. Ainsi, remplie de paradoxes et en marchant sur la corde raide des malentendus, l'écrivain belge Amélie Nothomb construit un personnage médiatique, dont la performance enferme une lecture aussi réfléchie dans son travail. Sur la ligne de frontière entre la fiction et la réalité - en supposant que ces deux termes peuvent s'opposer -, Amélie Nothomb garantit que son ethos pré-discursif soit renforcé par son discours, possibilité considérée par le linguiste Dominique Maingueneau.

MOTS-CLES : identité, espace biographiques, ethos, performance.

\footnotetext{
${ }^{1}$ Jornalista, Mestre em Teoria da Literatura e Literatura Comparada, Doutoranda em Literatura Comparada, Universidade do Estado do Rio de Janeiro. E-mail: anamelf@gmail.com
} 
ilha do barão e embaixador belga Patrick Nothomb, Amélie, a mais nova de três irmãos, nasceu em 13 de agosto de 1967, em Kobe, no Japão. O país, no qual viveu até os cinco anos e em direção ao qual sempre apontou sua profunda admiração, é frequentemente revisitado por Amélie Nothomb em suas obras.

Por conta das designações diplomáticas do pai, em seus primeiros 17 anos de vida Nothomb morou na China, nos Estados Unidos e em alguns países do sudeste asiático, antes de fixar residência na Bélgica. Em 1992, a escritora, já formada em filologia romana pela Universidade de Bruxelas, lançou seu primeiro romance, Hygiène de l'assassin (Higiene do Assassino, editora Presença), pela editora Albin Michel. De lá para cá, houve a disciplinada publicação de um romance por ano, e uma peça de teatro, em 1994 (Les Combustibless. Seus livros, que já foram traduzidos para cerca de 40 idiomas, são bem vendidos nos países europeus de língua francesa.

Em 1999, Amélie Nothomb lançou no mercado o romance Stupeur et tremblements (Medo e Submissão, editora Record), que recebeu, no mesmo ano, o Grande Prêmio de Romance da Academia Francesa. No ano seguinte, surgiu Métaphysique des tubes (Metafísica dos tubos, editora Record), que dialoga fortemente com seu antecessor. Os livros Hygiène de l'assassin e Stupeur et tremblements foram adaptados ao cinema, em 1999 e 2003, respectivamente.

Sempre "em cena", seja em seus romances ou nos meios de comunicação, a escritora, que é considerada como a "coqueluche das mídias" e a "queridinha" dos estudantes secundaristas francófonos, provoca em muitos críticos a classificação de narcisista e egocêntrica.

Assim como suas obras, povoadas de personagens "atípicos" e de temas como suicídio, anorexia e solidão, o comportamento excêntrico de Amélie Nothomb suscita polêmica. Colecionadora de chapéus escandalosos, adepta a um estilo de maquilagem que inclui rosto branco e batom escarlate, amante de frutas podres, capaz de girar o dedo polegar em 180 graus, a escritora, cujo próprio retrato é capa de inúmeros de seus livros, mantém correspondência abundante com seus leitores. Com alguns, essa troca epistolar dura anos, estabelecendo assim uma relação de intimidade que, em última análise, auxilia na construção de um "mito" dividido entre a crítica jornalística e a admiração ilimitada de uma parcela do público. 
Um dos episódios de maior repercussão em torno das aparições públicas da escritora diz respeito a seu declarado gosto por frutas podres. Depois de comer um pêssego podre "ao vivo e a cores" ", Nothomb faz tudo parecer um grande mal-entendido. Em entrevista ao site Fluctuat, em 2001, ela suaviza o impacto de suas aparições: "Eu não me considero particularmente excêntrica. As frutas podres, isso não é algo que eu tenha priorizado, foi a mídia que o fez e eu nunca compreendi qual o interesse. Os chapéus uso porque acho bonito, mas não é muito importante, pois não passa de uma peça de roupa e eu penso que não julgamos as pessoas por suas roupas. O batom é herança do Japão, onde as pessoas gostam que ele seja visto, o que me agrada muito. Não me incomoda se dizem que sou excêntrica, mas não vejo nada do que citei como excentricidade."3

As aparições da escritora Amélie Nothomb na mídia televisiva (em particular, a francesa) em geral ocasionam reações contrastantes. Essas presenças públicas, normalmente na época de lançamento de um novo romance (não esqueçamos, ela edita um romance por ano), contribuem enormemente para alimentar o "folclore" existente em torno daquela que é considerada por alguns críticos como "escritora-star".

Aparentemente consciente dos efeitos - positivos e negativos - dessa presença midiática, Nothomb dá a impressão de utilizar a mídia para criar fatos que - ela parece saber - atingirão sua imagem e serão "lidos" junto com sua obra. Dona de um humor peculiar, que pode igualmente ser conferido em seus escritos, Amélie Nothomb não poupa críticos e jornalistas, nem sequer si mesma, fazendo absoluta questão de caminhar sobre a corda-bamba dos mal-entendidos. Ela preserva, no entanto, a sua relação com seus inúmeros fãs, em sua maioria adolescentes e jovens adultos, criando uma sólida rede de identificações: "Após termos lido o seu livro, quando estamos diante dela não sabemos o que dizer, pois parece que já a conhecemos de cor", declara uma adolescente entrevistada pelo programa televisivo Esprits Libres (TV France 2), durante o lançamento do romance Ni d'Eve ni d'Adam, em Paris, em 22 de agosto de $2007 .{ }^{4}$

Estamos diante do que a teórica argentina Leonor Arfuch, em seu livro El espacio biográfico (2002), denomina como "identificação imaginária" de um sujeito que, por ser "constitutivamente incompleto", está aberto a "identificações múltiplas" daqueles que buscam uma "imagem de autorreconhecimento". No caso de Nothomb, que se declara povoada por uma legião de seres marginais, essa gama de identificações múltiplas é bastante vasta, incluindo os feios, os assassinos, os suicidas, os esfomeados, os deslocados, os submissos, os andróginos, os imperfeitos, os inacabados...

A conceituação de Leonor Arfuch, cujo texto aborda as escritas em primeira pessoa, tem perfeita sintonia com as respostas do sociólogo Zygmunt Bauman em seu livro-entrevista Identidade (2004): "Em nossa época líquido-moderna, em que o indivíduo livremente flutuante, desimpedido, é o herói popular, 'estar fixo' - ser 'identificado' de modo inflexível e sem alternativa - é cada vez mais malvisto” (BAUMAN, 2005, p. 35). Assim sendo, Bauman compara a composição da

\footnotetext{
${ }^{2}$ O episódio foi ao ar em 19 de setembro de 2000, no programa de variedades On n'a pas tout dit (TV France 2). Disponível em : $<$ http://www.youtube.com/watch?v=W3NZCWIXM0o>. Acesso em: 7 de dezembro de 2012.

${ }^{3}$ Entrevista com Amélie Nothomb realizada pelos jornalistas François Haget e Didier Hénique, em setembro de 2001, na ocasião de lançamento do romance Cosmétique de l'ennemi. Disponível em: < http://livres.fluctuat.net/amelie-nothomb/interviews/4631entretien.html>. Acesso em: 7 de dezembro de 2012. Tradução livre.

${ }^{4}$ Disponível em : <http://www.youtube.com/watch?v=LrjCohQgnvs>. Acesso em: 7 de dezembro de 2012.
} 
identidade com a montagem de um quebra-cabeça, frisando, entretanto, que, à diferença do jogo vendido nas lojas, "que vem completo em uma caixa", o quebra-cabeça biográfico é incompleto e tem muitas peças faltando.

Uma versão contextualizada da construção pública da identidade tentacular de Amélie Nothomb nos é oferecida por Laureline Amanieux, que escreveu uma tese sobre a escritora": "Temos a impressão de que ela cria um personagem na mídia, mas de fato é um personagem que é extremamente autêntico, esse é o paradoxo. Quer dizer que ela escreve sua obra e ela faz coro com sua obra. [...] Ao escrever, ela reconstrói sua identidade, uma identidade que foi submetida à destruição no fim da infância e na adolescência, mas, além disso, ela reconstrói sua identidade nessa relação com os leitores e com a mídia, para poder produzir uma imagem mais positiva dela mesma." ${ }^{\prime 6}$

\section{Nas escadas de Escher}

A mídia, notória ditadora de regras da sociedade contemporânea, é colocada em primeiro plano tanto por Leonor Arfuch quanto pelo sociólogo Zygmunt Bauman. Tendo por mola-mestra "a proliferação de narrativas vivenciais e seu impacto na (re)configuração da subjetividade contemporânea" (ARFUCH, 2002, p. 57), Leonor Arfuch define o que chama de "espaço biográfico" como um ponto de "confluência de múltiplas formas, gêneros e horizontes de expectativa". Este ponto de confluência abrangeria, ao lado das formas canônicas (biografias, autobiografia, memórias, diários etc.), outras fontes de registro vivencial como "os inúmeros registros biográficos da entrevista midiática", "velhas e novas variantes de shows - talk shows, reality shows"-, e até mesmo uma tendência qualificada pela pesquisadora como "exercício de ego-história", presente sobretudo na escritura acadêmica (ARFUCH, 2002, p. 49).

Bauman, por sua vez, defende que a flexibilidade deve rimar com a fluidez, uma vez que "num ambiente fluido, não há como saber se o que nos espera é uma enchente ou uma seca - é melhor estar preparado para as duas possibilidades" (BAUMAN, 2005, p. 57). Assim sendo, as estruturas não são mais confiáveis (ou sólidas), como na era pré-moderna e parecemos "habitar um universo desenhado por Escher, onde ninguém, em lugar nenhum, pode apontar a diferença entre um caminho ascendente e um declive acentuado" (BAUMAN, 2005, p. 58). Neste mundo volátil, o papel da mídia não é negligenciável: "Autoridades hoje respeitadas amanhã serão ridicularizadas, ignoradas ou desprezadas; celebridades serão esquecidas; ídolos formadores de tendências só serão lembrados nos quiz shows da TV; novidades consideradas preciosas serão atiradas nos depósitos de lixo [...]" (BAUMAN, 2005, p. 58).

Se o "espaço biográfico" foi ampliado, como quer Arfuch, e o mundo fluido de Bauman requer novas configurações identitárias, é certo que o papel do escritor também está sendo redefinido. Não apenas autor, ele é também ator, de forma que o "u" merece parênteses. Tanto por razões comerciais quanto por atuação performática, a circulação dos escritores no espaço midiático é inevitável. E mesmo os a(u)tores reclusos, como o norte-americano J. D. Salinger, têm sua opção

\footnotetext{
5 AMANIEUX, L. Amélie Nothomb : L'éternelle affamée. Paris, Albin Michel, 2005.

${ }^{6}$ Disponível em: <http://www.youtube.com/watch?v=LrjCohQgnvs>. Acesso em: 7 de dezembro de 2012.
} 
ruminada pela própria mídia. "Salinger foi um dos casos extremos de escritores engolidos pela própria obra. Arredio, invisível, ele se escondeu dentro de seus escritos e por isso foi não só um escritor genial, mas um personagem inesquecível. Pensamos em Salinger, que viveu longos anos recluso em uma fortaleza de Cornish, EUA, e, imediatamente, pensamos em Holden Caulfield, o narrador de 'O apanhador no campo de centeio', seu romance mais célebre'”, escreveu o escritor e crítico literário José Castello na ocasião do falecimento de Salinger, em 27 de janeiro de 2010.

A força motriz dos meios de comunicação de massa, dentre os quais incluímos a internet, obriga o mercado editorial a criar gradativamente novas formas de legitimação e de consagração. As feiras literárias ganham proporções de eventos voltados ao grande público, com números astronômicos ${ }^{8}$. Livros são inteiramente compostos em blogs, inaugurando uma parceria que confunde os papéis entre escritores e leitores, e até eliminando, por vezes, a necessidade da publicação. Entrevistas e pesquisas de referências criam formas de leituras cruzadas, modificando a recepção dos textos. Esses são apenas alguns exemplos. Uma das consequências de tal movimento é que cada vez mais é exigido que os escritores acumulam a função de promotores de suas obras. Função que Amélie Nothomb não se priva de desempenhar, quase que com a mesma disciplina com que escreve (e publica) suas obras.

Retomando as palavras de Laureline Amanieux anteriormente mencionadas, Amélie Nothomb "reconstrói sua identidade nessa relação com os leitores e com a mídia". A própria escritora confirma que sua produção literária é um espelho. No programa "La Grande Librairie", apresentado em 03 de setembro de 2009 na rede de televisão francesa France 5, a escritora, ao ouvir a pergunta “o que fazer para saber quem é você de verdade?", feita pelo apresentador François Busnel, responde: "Acho que é realmente necessário ler meus livros [...], eu mesma, quando quero saber, os releio um pouco e digo a mim mesma: ah, sim, talvez, no fim das contas, seja isso". No mesmo programa, em uma apresentação sobre a escritora, ela define como é possível escrever sobre si mesma e preservar a intimidade: "penso que é possível, desde que estejamos todo o tempo na linha de fronteira".

A ideia da interpenetração entre vida e obra não é nova e serve de base ao que o linguista francês Dominique Maingueneau chama de bio/grafia. No capítulo intitulado "Obra, escritor e campo literário", do livro O contexto da obra literária: enunciação, escritor, sociedade (1995), Dominique Maingueneau define o que intitula bio/grafia, cuja barra de separação significa a via de ida e volta entre os dois termos, ou seja, "da vida rumo à grafia ou da grafia rumo à vida." (MAINGUENEAU, 1995, p. 46). Segundo o linguista, "o importante é a maneira particular como o escritor se relaciona com as condições de exercício da literatura de sua época" (MAINGUENEAU, 1995, p. 45), já que "o escritor 'vive' entre aspas a partir do momento em que sua vida é dilacerada pela

\footnotetext{
<http://oglobo.globo.com/blogs/prosa/posts/2010/01/28/jose-castello-comenta-morte-de-d-salinger-261480.asp>. Acesso em: 11 de dezembro de 2012.

${ }^{8}$ Conferir: “Mais de 600 mil passam pela Bienal do Livro no Rio”. < http://g1.globo.com/ Sites/Especiais/Noticias/0,,MUL131139116727,00-MAIS+DE+MIL+PASSARAM+PELA+ BIENAL+DO+LIVRO+NO+RIO.html>. Acesso em: 11 de dezembro de 2012.

9 Disponível em: <http://www.france5.fr/la-grande-librairie/index.php?page=article\&numsite=1403\&id_article=12392\&id_ rubrique $=1406>$. Acesso em: 11 de dezembro de 2012. Tradução livre.
} 
exigência de criar, em que o espelho já se encontra na existência que deve refletir"' (MAINGUENEAU, 1995, p. 47).

Essa dilaceração é verbalizada pela escritora Amélie Nothomb em muitas de suas entrevistas, tal como na supracitada, quando afirma buscar-se em seus próprios personagens. Ela também revela, em diversas ocasiões, aquilo que seria a chave de seu sucesso literário, ou seja, a disciplina. Para publicar 18 livros em 18 anos de carreira, conta exata que a faz participar de todas as rentrées littéraires francesas, Amélie Nothomb diz escrever religiosamente todos os dias, durante quatro horas, entre $4 \mathrm{~h}$ e $8 \mathrm{~h}$ da manhã. ${ }^{10} \mathrm{~A}$ declaração de Nothomb exemplifica o que Dominique Maingueneau chama de rites génétiques, através dos quais o escritor estabelece "um modo de vida capaz de tornar possível uma obra singular" (MAINGUENEAU, 1995, p. 48).

Assim sendo, Maingueneau sustenta que "a obra só pode surgir se, de uma maneira ou de outra, encontrar sua efetuação numa existência" (MAINGUENEAU, 1995, p. 54). No caso de Amélie Nothomb, acreditamos que é justamente a performance - ou o jogo dos mal-entendidos, como expressamos anteriormente - que define seu posicionamento no campo literário. A performance a que nos referimos - que pode designar tanto "atuação, desempenho", quanto o "espetáculo no qual o artista fala e age por conta própria" 11 - inclui um tipo de ambiguidade que representa o ethos da escritora, como veremos posteriormente, e que, ao mesmo tempo, inscreve sua paratopia. Afinal, com Amélie Nothomb nunca sabemos ao certo onde começa a ficção. Não por acaso, ela mesma é uma de suas grandes personagens e a literatura, um de seus grandes temas.

A ambiguidade povoa as linhas escritas por Amélie Nothomb, mesmo quando a protagonista de sua obra não é declaradamente fictícia. Sem discutir a questão genérica de seus romances - é autobiografia ou autoficção? -, buscamos em duas obras escritas quase que integralmente em primeira pessoa exemplos que sustentam a nossa hipótese: Métaphysique des tubes (2000) e Biographie de la faim (2004).

Em Métaphysique des tubes ${ }^{12}$, o enredo aborda os três primeiros anos de vida de uma criança belga nascida no Japão, a partir das impressões de seu estreito relacionamento com a babá Nishiosan. Sem memórias de sua vida até os dois anos e meio de idade, a protagonista, vítima de uma "apatia patológica", é qualificada por todos e por si mesma como um "tubo". É a partir do que seria o "olhar de um tubo" que a narradora intradiegética analisa as relações familiares e a experiência divina. Até o dia de seu "nascimento", quando o "tubo" se torna "eu": "C'est moi! C'est moi qui vis! C'est moi qui parle! Je ne suis pas 'il' ni 'lui', je suis moi! Tu ne devras plus dire 'il' pour parler de toi, tu devras dire 'je'. [...] Ce fut alors que je naquis, à l'âge de deux ans et demi [...]” (MT, p. 30).

O décimo-segundo romance publicado por Amélie Nothomb, Biographie de la faim ${ }^{13}$, dia-

10 Conferir em: <http://www.france5.fr/la-grande-librairie/index.php?page=article\&numsite = 1403\&id_article=12392\&id_ rubrique $=1406>$. Acesso em: 11 de dezembro de 2012. / “C'est en 1989 que je me mis à écrire à plein regime. [...] C'est là que j'adoptai ce qui est devenu mon rythme: consacrer un minimum de quatre heures par jour à l'écriture.” (La Biographie de la faim, p. 185).

${ }^{11}$ Dicionário Aurélio Século XXI - versão eletrônica.

${ }^{12}$ As citações desse livro serão indicadas através do número das páginas precedido pela sigla MT.

${ }^{13}$ As citações desse livro serão indicadas através do número das páginas precedido pela sigla BF. 
loga fortemente com vários outros livros da escritora, especialmente com Métaphysique des tubes. A protagonista, igualmente uma criança com inúmeras coincidências biográficas com a autora, tenta incessantemente preencher o vazio que a qualifica (em Métaphysique, como já dissemos, a criança era um 'tubo'), seja através das paisagens dos países que habita, seja através das pessoas que ama, seja através das leituras que faz, seja, simplesmente, através da potomania que adquire.

Logo no início de Biographie de la faim, a narradora, sempre com um humor peculiar, relata a situação em que sua mãe tentava identificá-la ao pai, desde seus primeiros anos de vida : "Ma mère décida très vite que j'étais mon père. Là où il avait une ressemblance, elle vit une identité. Quand j'avais trois ans, j'accueillais les hordes d'invités de mes parents en leur affirmant d'un ton las : 'Moi, c'est Patrick'. Les gens étaient stupéfaits' (BF, p. 29). Alguns anos mais tarde, seu duplo passou a ser sua irmã, Juliette : "Au Bangladesh débuta notre processus de ressemblance. Nous ne l'avions ni décidé ni remarqué. Vivre à deux sur le même canapé favorisa ce phénomène. Nous grandissions sur le modèle du double" (BF, p. 140). Juliette, que é o nome verdadeiro da irmã de Amélie Nothomb, é personagem de inúmeros romances da autora. Se nos livros Juliette é personagem-símbolo da perfeição, fora da ficção não é diferente. Em suas entrevistas, Amélie não cessa de expressar sua idolatria pela irmã mais velha.

Em Métaphysique des tubes, a fonte de ambiguidades é sobretudo a identidade nacional: "Il y avait beaucoup de différences sur terre : les Japonais et les Belges (je croyais que tous les Blanc étaient belges, sauf moi qui me tenais pour japonaise)" (MT, p. 82). A identidade japonsesa, aliás, é fortemente perseguida pela narradora de Amélie Nothomb em vários romances, especialmente Stupeur et tremblements e Ni d'Eve ni d'Adam. A ficção de ser japonesa conduz a narradora de Métaphysique des tubes a descobrir o prazer da invenção : "Il fallait que je me fasse à cette idée: je n'étais pas crédible. Ce n'était pas grave. Au fond, cela m'était égal, qu'on me croie ou non. Je continuerais à inventer, pour mon plaisir. Je me mis donc à me raconter des histoires. Moi au moins, je croyais à ce que je me disais" (MT, p. 115). Em Biographie de la faim, é a incompreensão da nacionalidade belga que leva ao prazer da escrita: "De tous les pays où j’ai vécu, la Belgique est celui que j’ai le moins compris. C'est peut-être cela, être de quelque part: ne pas voir de quoi il s'agit. Sans doute est-ce pour cette raison que j'y commençais à écrire. Ne pas comprendre est un sacré ferment pour l'écriture. Mes romans mettaient en forme une incomprehénsion qui croissait" (BF, p. 179).

Como diz Laureline Amanieux, Amélie Nothomb "escreve sua obra e faz coro com sua obra". Alguns de seus personagens fictícios, como o Prétextat Tach, de Hygiène de l'assassin (1992), ou Aliénor Malèze, de Le Voyage d'hiver (2009), são escritores. Nos romances que abordamos, a protagonista também revela a importância da leitura e da escrita em sua vida. Nem isso, entretanto, é tão transparente quanto aparenta. Se tudo permite supor que Biographie de la faim é autobiográfico - até mesmo declarações de sua autora -, a narradora não cessa de jogar com as certezas do leitor:

Si ces pages en parlent à peine, c'est par souci d'authenticité envers le délire d'une gosse de huit ans. Je ne prétends pas même avoir habité à New York: j’ai été pendant trois ans une enfant qui vivait New York comme une folie. (p. 81) 
Juliette était mon existence et j'étais la sienne. [...]

Un jour, je lui avouais que j'écrivais. [...]

Elle lut donc mon histoire d'oeuf. Je n'attendais pas d'elle une appréciation.

Elle me rendit avec pour unique commentaire:

- C'est autobiographique.

En effet, dans l'oeuf géant, le jaune n'avait pas résisté au coup d'État des jeunes révolutionnaires. Il s'était répandu dans le blanc et cette apocalypse de lécithine avait provoqué l'explosion de la coquille. L'oeuf s'était alors métamorphosé en une titanesque omelette spatiale qui évoluerait dans le vide cosmique jusqu'á la fin du temps.

Oui, ce devait être ça, une autobiographie. (p. 180-1)

\section{Ethos e construção identitária}

$\mathrm{Na}$ coletânea de textos Cenas da enunciação, está incluído o artigo "Problemas de ethos"14, em que Dominique Maingueneau aborda minuciosamente a questão. Considerando que "a questão do ethos está ligada à construção da identidade” (MAINGUENEAU, 2008, p. 59), o linguista francês determina que "o ethos está crucialmente ligado ao ato de enunciação, mas não se pode negar que o público constrói também representações do ethos do enunciador antes mesmo que ele fale" (MAINGUENEAU, 2008, p. 60). Essa representação prévia é chamada por Maingueneau de ethos pré-discursivo, podendo estar diretamente ligada à presença na cena midiática, por exemplo: "O ethos se elabora, assim, por meio de uma percepção complexa que mobiliza a afetividade do intérprete, que tira suas informações do material linguístico e do ambiente” (MAINGUENEAU, 2008, p. 61). Precisando a conceituação, Maingueneau acrescenta que "o ethos, por natureza, é um comportamento que, enquanto tal, articula verbal e não-verbal para provocar no destinatário efeitos que não decorrem apenas das palavras" (MAINGUENEAU, 2008, p. 61).

Ao longo de sua carreira literária, em suas aparições públicas e em seu material de divulgação, Amélie Nothomb aposta na surpresa, no inesperado. Ela pode tanto aparecer com ares de gueixa $^{15}$, ou com uma gota negra pintada abaixo do olho ${ }^{16}$, quanto absolutamente sóbria e elegante $^{17}$. O tom e o teor de suas declarações se deslocam em semelhante movimento, tendo o humor como fio condutor constante. No contato com o público, entretanto, como nas sessões de autógrafo, por exemplo, ela se mostra bastante receptiva. ${ }^{18}$

Ao construir, assim, o ethos pré-discursivo da imprevisibilidade e da pluralidade, Nothomb favorece uma série de identificações que constituem a "comunidade imaginária daqueles que ade-

\footnotetext{
${ }^{14}$ Artigo publicado originalmente na revista Pratiques $n^{\circ} 113$, junho de 2002, p. 55-68.

${ }^{15}$ Conferir foto da capa de Ni d'Eve ni d'Adam. Edição de referência: NOTHOMB, A. Ni d'Ève ni d'Adam. Paris: Éditions Albin Michel, 2007

${ }^{16}<$ http:/ /www.youtube.com/watch?v=-h4Tf2NOQqg\&NR=1>. Acesso em: 15 de dezembro de 2012.

${ }^{17}$ Entrevista na ocasião de lançamento de Le Voyage d'hiver, em 05 de agosto de 2009. Disponível em: <http://www.youtube.com/ watch?v=MuUQiAwI6e8\&feature=related $>$. Acesso em: 15 de dezembro de 2012.

${ }^{18}$ Conferir, por exemplo: <http://www.youtube.com/watch?v=LrjCohQgnvs\&feature=related $>$. Acesso em: 15 de dezembro de 2012.
} 
rem ao mesmo discurso" (MAINGUENEAU, 2008, p. 65). Não por acaso, boa parte de seus leitores é formada por adolescentes e jovens adultos, em notória fase de formação identitária.

O ethos pré-discursivo pode ser reforçado ou transformado pelo discurso. Compreendendo como "fiador" o enunciador do discurso, Dominique Maingueneau sentencia:

Assim, acaba-se por atribuir ao fiador um 'caráter' e uma 'corporalidade', cujo grau de precisão varia segundo os textos. O 'caráter' corresponde a um feixe de traços psicológicos. Quanto à 'corporalidade', ela é associada a uma compleição física e uma forma de se vestir. Além disso, o ethos implica uma forma de moverse no espaço social, uma disciplina tácita do corpo, apreendida por meio de um comportamento. O destinatário o identifica apoiando-se em um conjunto difuso de representações sociais, avaliadas positiva ou negativamente, de estereótipos, que a enunciação contribui para reforçar ou transformar. (MAINGUENEAU, 2008, p. 65)

Com base na análise acima mencionada, acreditamos que o ethos discursivo de Amélie Nothomb confirma o seu ethos pré-discursivo, ocasionando a própria instabilidade de sua aceitação no campo literário. As críticas dirigidas ao estilo midiático de Amélie Nothomb são tão contrastantes quanto o comportamento da escritora. Por exemplo:

C'est la star rock'n'roll de la littérature: 17 romans, tous best-sellers, traduits en 40 langues et étudiés dans 12 universités américaines. ${ }^{19}$

'Quand on reçoit le dernier Nothomb, on est prévenu: c'est la fin des vacances!' ironisait, le 9 septembre 2001 au micro du Masque et la Plume, Jean-Louis Ezine, le critique littéraire du Nouvel Observateur. ${ }^{20}$

Ainsi, les pages littéraires du New York Times s'ouvrent de plus en plus aux ouvrages étrangers récemment traduits, et aux auteurs francophones. [...] Cette semaine, c'est Amélie Nothomb, avec Tokyo's Fiancée (Traduction de son Ni Eve, ni d'Adam), de s'attirer les éloges du prestigieux quotidien : 'une histoire d'amour délicieusement absurde', 'un roman économe et élégant', 'elle restitue l'exotisme de la culture japonaise sans recourir aux stéréotypes'. Après avoir conquis France, Belgique et Japon, Amélie Nothomb va-t-elle envahir l'Amérique ?21

Marie Nimier en Bécassine, Jean-Marc Parisis en Philip Marlowe, Joyce Carol Oates et Emily Dickinson [...]. Ce sont quelques-uns des quarante auteurs enfilant, pour l'objectif de Stéphane Haskell, le costume de leur personnage préféré. Le résultat est étonnant et révélateur : Sollers se prend pour le marquis de Sade, To-

\footnotetext{
19 “Les vérités d'Amélie Nothomb”, por Gilles Médioni, publicado na revista L’Express em 25 de setembro de 2008. Disponível em : < http://www.lexpress.fr/culture/livre/les-verites-d-amelie-nothomb_823051.html>. Acesso em : Acesso em: 15 de dezembro de 2012.

20 "Les silences d'Amélie", por Daniel Garcia, publicado na revista L'Exxpress em 01 de setembro de 2006. Disponível em: http:// www.lexpress.fr/culture/livre/les-silences-d-amelie_811533.html. Acesso em: 15 de dezembro de 2012.

21 “Amélie Nothomb vantée par le New York Times". Disponível em: http://www.magazine-litteraire.com/content/recherche/ article?id=12447. Acesso em: 15 de dezembro de 2012.
} 
nino Benacquista pour Mr Hyde et Amélie Nothomb décide que son personnage préféré est... Amélie Nothomb! Bon sang, mais c'est bien sûr! ${ }^{22}$

Ainda em seu artigo "Problemas de ethos", Dominique Maingueneau aborda a aproximação entre ethos e discurso publicitário, avalizando nossa proposta de reconfiguração do mercado literário e de suas formas de consagração, na qual escritores acumulam a função de promotores de suas obras. $\mathrm{Na}$ consideração de Maingueneau, "o discurso publicitário contemporâneo mantém, por natureza, um laço privilegiado com o ethos; de fato, ele procura persuadir associando os produtos que promove a um corpo em movimento, a uma maneira de habitar o mundo [...]" (MAINGUENEAU, 2008, p. 66).

No discurso publicitário de um mercado editorial que precisa dar conta de concorrências cada vez mais devoradoras, o livro é um produto comercializado junto com o ethos de seu a(u)tor: “eu leio o livro de x, logo me incluo na 'tribo' de x”. Prova cabal é a elaboração de perfis de jogadores de programas de telerrealidade a partir das obras que estão lendo (no ar) ${ }^{23}$. Pertencimento a uma "tribo" significa, obviamente, padrão de comportamento. De maneira antropofágica, o mercado editorial teve que deslocar do produto para a imagem do produto a sua forma de "habitar o mundo". "Os estereótipos de comportamento eram outrora acessíveis às elites de maneira privilegiada por meio da leitura dos textos literários, enquanto, hoje, esse papel é atribuído à publicidade, sobretudo em sua forma audiovisual", escreve Maingueneau, completando:

A especificidade de um ethos remete, de fato, à figura de um 'fiador' que, por meio de sua fala, se dá uma identidade em acordo com o mundo que ele supostamente faz surgir. [...] As 'ideias' suscitam a adesão do leitor por meio de uma maneira de dizer que é também uma maneira de ser. Tomado pela leitura em um ethos envolvente e invisível, participa-se do mundo configurado pela enunciação, acede-se a uma identidade de certa forma encarnada. (MAINGUENEAU, 2008, p. 72)

Sob este olhar, a escritora Amélie Nothomb parece ter compreendido com absoluta clareza sua função diante do mundo do espetáculo e da performance, que não poupa nem mesmo os que negam tal configuração. E, mais um paradoxo nothombiano, quando o assunto é o papel do escritor na contemporaneidade, ela demonstra um entendimento nada opaco:

Dans l'oeuvre de Bret Easton Ellis, on retrouve aussi des personnages insensibles, tel Patrick Bateman, qui n'ont du plaisir qu'en tuant. Que pensez-vous de cet auteur et de son univers ? C’est une sacrée métaphore de notre société moderne : la société de consommation poussée à son comble. Car derrière les produits, la matière de tout ce qu'on achète, il s'agit d'êtres humains. Le serial killer est celui

\footnotetext{
22 "Des écrivains et leurs doubles", artigo publicado no jornal Le Figaro, em 19 de dezembro de 2008. Disponível em: <http:/ /www. lefigaro.fr/lefigaromagazine/2008/12/20/01006-20081220ARTFIG00085--des-ecrivains-et-leurs-doubles-.php>. Acesso em: 15 de dezembro de 2012.

${ }^{23}$ Conferir em <http://www.country.com.br/so/tag/Lendo>. Acesso em: 15 de dezembro de 2012.
} 
qui pousse à l'extrême le principe même de la société de consommation. C'est évidemment une chose qui me paraît effrayante mais qui est très révélatrice de notre fonctionnement actuel. C'est en cela que les livres de Bret Easton Ellis sont intéressants et c'est peut-être pour ça qu'Urbain est tueur à gages. ${ }^{24}$

Urbain, protagonista de Journal d'Hirondelle (2006), é um assassino em série que muda constantemente de identidade. Prétextat Tach, protagonista de Hygiène de l'assassin (1992), também carrega um assassinato em suas costas. Em Robert des noms propres (2002), a narradora é assassinada ao final do romance. A aproximação entre escritura e morte é uma constante nas obras de Nothomb, cujos personagens pretensamente autobiográficos de Biographie de la faim e Métaphysique des tubes se autoconsideravam Deus. Em suas entrevistas, ela reitera essa projeção do 'escritor assassino' e afirma que, apesar de ter vontade de matar seu próximo, “como todo mundo tem”, a única pessoa que teria coragem de assassinar seria ela mesma. ${ }^{25}$

A constante construção e reconstrução pública de Amélie Nothomb espelha, enfim, o próprio "caráter ilusório da identidade", como diz Bauman, que encontra, na contemporaneidade, todos os canais para que essa identidade seja "usada e exibida". Em uma sociedade marcada pelo consumo, "todos estamos dentro e no mercado, ao mesmo tempo clientes e mercadorias" (BAUMAN, 2005, p. 98), incluindo os escritores. Assim, tomando os conceitos de Bauman, não há possibilidades de tornar sólido o que já é líquido, uma vez que "num ambiente de vida líquido-moderno, as identidades talvez sejam as encarnações mais comuns, mais aguçadas, mais profundamente sentidas e perturbadoras da ambivalência” (BAUMAN, 2005, p. 38).

Se na questão da identidade a ambivalência é genuína, como diz Bauman, a metáfora da fênix, da qual poderia se valer Nothomb para analisar sua posição no campo literário, é igualmente genuína. Afinal, o papel do escritor neste mercado submisso, ele também, às regras do consumo, pode bem ser o do assassino que mata publicamente alguns comprometimentos - aprofundamento de temas complexos e coerência de estilo, por exemplo - para que em seguida, como Deus, possa criar alguns outros mecanismos de legitimação, como redes de identificação, intertextualidade e manutenção produtiva.

\section{REFERÊNCIAS BIBLIOGRÁFICAS:}

ARFUCH, L. El espacio biográfico. Buenos Aires: Fondo de Cultura Económica, 2002.

BAUMAN, Z. Identidade. Entrevista a Benedetto Vecchi. Tradução de Carlos Alberto Medeiros. Rio de Janeiro: Zahar, 2005.

MAINGUENEAU, D. O contexto da obra literária: enunciação, escritor, sociedade. Tradução de Marina Appenzeller. São Paulo: Martins Fontes, 1995.

\footnotetext{
${ }^{24}$ Conferir em: <http://www.evene.fr/celebre/actualite/interview-amelie-nothomb-journal-hirondelle-561.php>. Acesso em: 15 de dezembro de 2012.

${ }^{25}$ Conferir : <http://livres.fluctuat.net/amelie-nothomb/interviews/4631-entretien.html>. Acesso em: 15 de dezembro de 2012.
} 
Cenas da enunciação. Organização de Sírio Passenti e Maria Cecília Pérez de Souza-e-Silva. São Paulo: Parábola Editorial, 2008.

NOTHOMB, A. Métaphysique des tubes. Paris: Éditions Albin Michel, Collection Le Livre de Poche, 2000.

Biographie de la faim. Paris: Éditions Albin Michel, Collection Le Livre de Poche, 2004. 